\title{
Treatment of Axillary hyperhidrosis
}

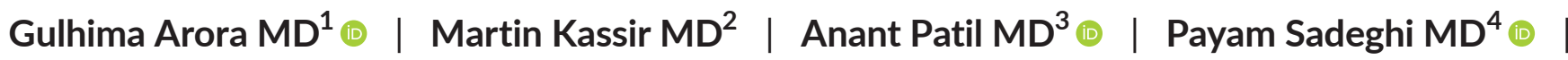 \\ Michael H. Gold MD ${ }^{5}$ - | Maurice Adatto MD ${ }^{6}$ | Stephan Grabbe MD ${ }^{7}$ | \\ Mohamad Goldust MD ${ }^{8}$
}

\author{
${ }^{1}$ Department of Dermatology, Mehektagul \\ Dermaclinic, New Delhi, India \\ ${ }^{2}$ Worldwide laser institute, Dallas, Texas, \\ USA \\ ${ }^{3}$ Department of Pharmacology, Dr. DY \\ Patil Medical College, Navi Mumbai, India \\ ${ }^{4}$ Department of Plastic Surgery, Cleveland \\ Clinic, Cleveland Clinic Main Campus, \\ Cleveland, Ohio, USA \\ ${ }^{5}$ Gold Skin Care Center, Tennessee Clinical \\ Research Center, Nashville, Tennessee, \\ USA \\ ${ }^{6}$ Skinpulse Dermatology and Laser Centre, \\ Geneva, Switzerland \\ ${ }^{7}$ Department of Dermatology, University \\ Medical Center of the Johannes \\ Gutenberg University, Mainz, Germany \\ ${ }^{8}$ Department of Dermatology, University \\ Medical Center Mainz, Mainz, Germany \\ Correspondence \\ Mohamad Goldust, MD, Department of \\ Dermatology, University Medical Center \\ Mainz, Mainz, Germany. \\ Email: mgoldust@uni-mainz.de
}

\begin{abstract}
Background: Axillary hyperhidrosis characterized by excessive sweating in the axillary regions is a frustrating chronic autonomic disorder leading to social embarrassment, impaired quality of life and usually associated with palmoplantar hyperhidrosis. Identifying the condition and its cause is central to the management.

Aim: The aim of this article is to discuss treatment options for axillary hyperhidrosis. Methods: Comprehensive literature search using PubMed and Google Scholar was performed to review relevant published articles related to diagnosis and treatment of axillary hyperhidrosis.

Results: Treatment modalities for axillary hyperhydrosis vary from topical and systemic agents to injectables, newer devices and surgical measures. None except for physical measures using devices or surgery, which destroys the sweat glands to remove them, is possibly permanent and most are associated with attendant side effects. Conclusion: Several treatments including medical and surgical option are available for the treatment of axillary hyperhydrosis. Patient education is important component of its management. Individualized approach of management is necessary for optimal outcome of treatment.
\end{abstract}

KEYWORDS

Axillary hyperhidrosis, sweating, treatment

\section{INTRODUCTION}

Hyperhidrosis is a frustrating chronic autonomic disorder with frequent recurrences. Its overall and self-reported prevalence is $17.9 \%$ and $10.2 \%$, respectively. ${ }^{1}$ Hyperhidrosis may be primary, usually focal and bilateral, or secondary which is generalized. ${ }^{2}$ Focal hyperhidrosis is usually idiopathic and localized to the palms, soles, axilla, or craniofacial areas. Primary hyperhidrosis may be an autosomal dominant genetic disorder with incomplete penetrance. About $31.5 \%-65 \%$ of patients in different studies had a positive family history. ${ }^{3,4}$ Generalized hyperhidrosis is usually related to a drug or systemic condition. ${ }^{5}$ Axillary hyperhidrosis (AH) is increased and excessive sweating localized to the armpits beyond what is necessary for thermal regulation. ${ }^{6}$ It may range from slight dampness to severe dripping. Sweating is a physiological condition necessary for thermoregulation, excretion, and microbial defense. ${ }^{7}$ However, its excess may lead to an exacerbation of many localized skin conditions, an embarrassment due to staining of clothes or a foul odor at times, depression, and socially anxiety with a lowered quality of life. ${ }^{4}$ It is essential to know the causes, mechanisms of production, and effects of hyperhidrosis to be able to manage it effectively.

This is an open access article under the terms of the Creative Commons Attribution-NonCommercial License, which permits use, distribution and reproduction in any medium, provided the original work is properly cited and is not used for commercial purposes.

(c) 2021 The Authors. Journal of Cosmetic Dermatology published by Wiley Periodicals LLC. 


\section{2 | THE SWEAT GLANDS}

There are three types of sweat glands in the axilla: eccrine, apocrine, and apoeccrine glands. (Figure 1) Eccrine glands become functional soon after birth. Apocrine glands start to function only under hormonal stimulation at puberty. The total number of sweat glands in an individual vary from two to four million with a higher concentration in the palms, soles, and axillae. ${ }^{8}$ The innervation of the eccrine glands is via cholinergic and sympathetic postganglionic unmyelinated C-fibers. ${ }^{8,9}$ These are under the control of the hypothalamus. Acetylcholine is the primary neurotransmitter, ${ }^{10}$ with little contribution of norepinephrine stimulating the adrenergic terminals. ${ }^{11}$ This is different from all other postganglionic sympathetic fibers, which release norepinephrine. Cholinergic stimulation of muscarinic receptors initiates sweat production. The apocrine glands are innervated by postganglionic sympathetic nerves with norepinephrine is the primary neurotransmitter and thus they respond to emotional sweating. ${ }^{12}$ Sweat glands in the axilla are activated by emotional and thermosensitive stimuli which activate the hypothalamic sweat centers. The center in charge of emotional sweating is controlled by the cortex and different from the other sweat centers, which receive inputs from thermosensitive stimuli. It is postulated that primary hyperhidrosis is due to an abnormal central control of emotional sweating. ${ }^{13}$ The effect of acetylcholinesterase is reduced when the sweating increases. ${ }^{11}$ The effect of neuropeptides such as vasoactive intestinal polypeptide, substance $P$, nitric oxide, and calcitonin gene-related peptide have been implicated in causing cutaneous vasodilatation ${ }^{14}$ and sweating. All except substance $P$ have been known to exacerbate sweat rate. ${ }^{15}$ The central sudomotor efferent pathway is shown in (Figure 2).

\section{3 | MANAGEMENT}

Central to managing hyperhidrosis is diagnosing the condition, identifying the cause, and addressing it. The diagnostic criteria

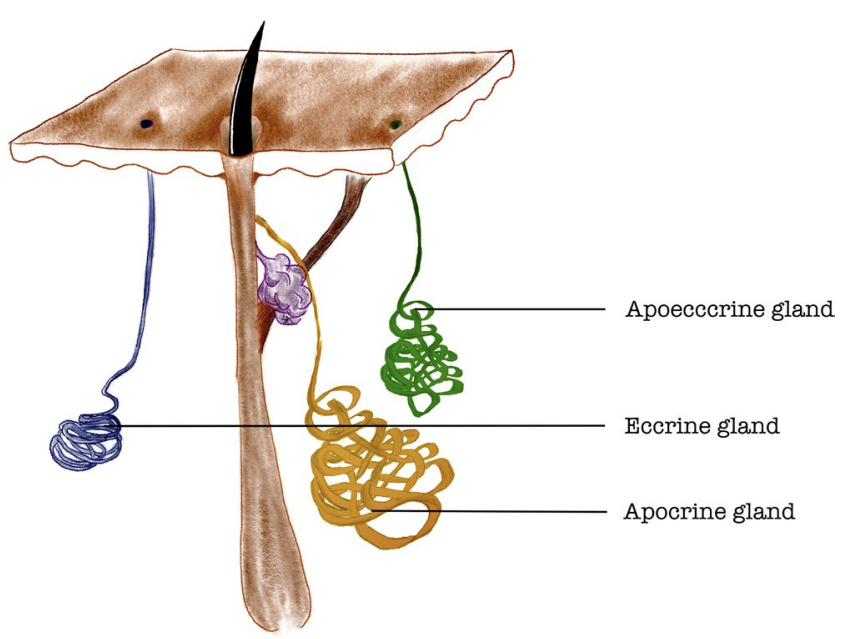

FIGURE 1 Types of sweat glands in the axillary region of hyperhidrosis include excessive sweating lasting for at least 6 months without any cause, with at least two more criteria: age of onset less than 25 years, cessation of sweating during sleep, bilateral, relatively symmetrical pattern of sweating with at least one episode a week or a positive family history. ${ }^{16}$ The Hyperhidrosis Disease Severity Scale (HDSS) helps to gauge the impact of the disorder in the patient's life, plan the treatment modality, and gauge the response to treatment and to get disability compensation. $(\text { Box } 1)^{17}$

Treatment options are safe and effective (Table 1), and however, there is no cure. ${ }^{2}$ Treatment decisions should be according to the patient and the quality of evidence available for a particular treatment. General advice to be given is shown in Box $2{ }^{2}$

\section{4 | TOPICAL TREATMENTS}

Topical therapies are the first-line treatment of $\mathrm{AH}^{17}$ because of their ease of use, clinical, and cost-effectiveness.

\section{1 | Antiperspirants}

Patients with a low HDSS score benefit from the use of antiperspirants. These may be sprays, gels, or wipes. Prescription antiperspirants contain aluminum chloride hexahydrate in concentrations ranging from $6.25 \%$ to $40 \%$ in an ethanol vehicle. In a case series, $15 \%$ solution was as effective as a $20 \%$ and was better tolerated. Lower strengths are less effective and used for those with a sensitive skin. ${ }^{19}$ The aluminum ions are said to precipitate mucopolysaccharides, which damage the epithelial cells of the duct, which plug the lumen. They mechanically block the sweat gland openings and prevent sweat release. ${ }^{20}$ The plugs are dislodged with more sweat production, making reapplication necessary after 6-8 h. They are used on a dry skin while sleeping. ${ }^{18}$ They may cause skin irritation which is mild and transient. ${ }^{2}$ In one study, treatment-limiting irritation was found in $26 \%$ of patients. ${ }^{21}$ One of the most common adverse effects of the chloride formulation is itching and stinging. In a series of 691 patients, $70 \%, 21 \%$, and $9 \%$ patients had mild, moderate, and severe pruritus, respectively. ${ }^{19}$

Other compounds such as aluminum chloride, a partially neutralized form found in cosmetics and aluminum zirconium tetrachlorohydrex (AZT) a newer compound with claims of less skin irritation is being used. Aluminum chloride is less effective than aluminum hexahydrate. ${ }^{22,23}$ Many over-the-counter (OTC) clinical-strength antiperspirants contain AZT. This compound reduces the production of $\mathrm{HCl}$ on the skin by $80 \%$ and is hence less irritating. Its blockage of the sweat ducts, however, is more superficial than $\mathrm{AH}$.

In a study, a clinical-strength OTC antiperspirant was on an average $34 \%$ more effective than a $6.5 \%$ aluminum chloride topical. ${ }^{22}$ Newer vehicles such as salicylic acid $4 \%$ have also been used as a vehicle for aluminum chloride. It enhances the absorption of aluminum 


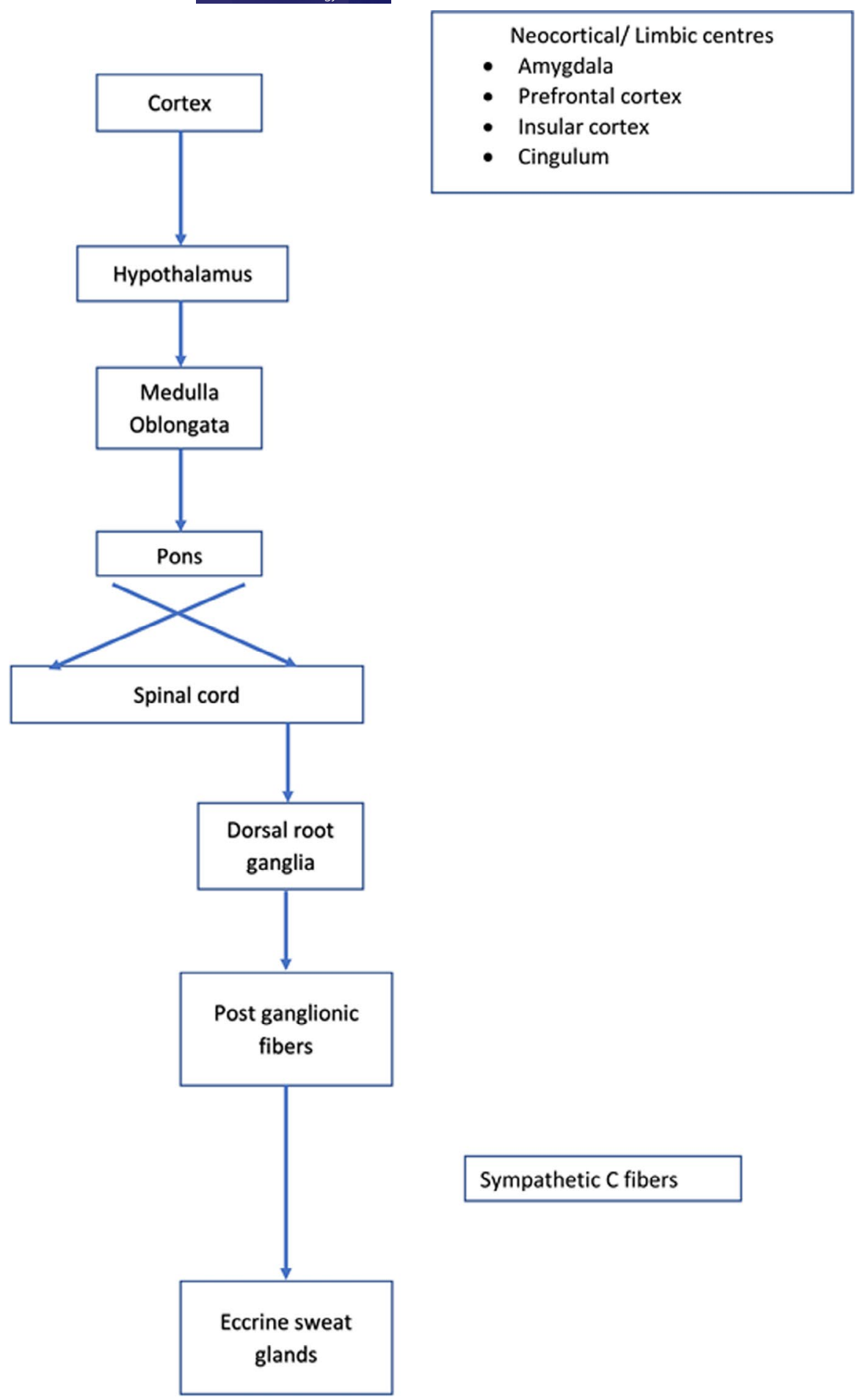

FIGURE 2 Central sudomotor efferent pathway chloride and has additional antiperspirant effects. ${ }^{22}$ Recently, a lowresidue thermophobic foam formulation containing $20 \%$ aluminum sesquichlorohydrate has been tested for $\mathrm{AH}^{24}$

\section{2 | Topical anticholinergics}

Glycopyrrolate $1 \%-2 \%$ spray or solution has been used with varying degrees of success. Formulation with $2 \%$ strength has shown to be superior to the $1 \%$ ones. It can be applied twice daily or once at night. Xerostomia, urinary hesitance, and mydriasis have been reported as side effects. It is not very promising in $\mathrm{AH}$ as shown in a study of 35 patients using $1 \%$ glycopyrrolate in cetomacrogol cream BP who failed to show any consistent results with this drug after using it once daily for 1 month. ${ }^{25,26}$

Glycopyrronium tosylate (GT) $2.4 \%$ cloth is a US FDA-approved treatment for primary $\mathrm{AH}$ for patients 9 years and above of age. ${ }^{27} \mathrm{~A}$ study by Hebert AA et al. (4-week double-blind plus 44-week open label) concluded that a once daily GT application for up to 48 weeks was an effective and well-tolerated treatment option for $\mathrm{AH}$ in 


\section{BOX 1 HDSS $^{17}$}

Ask the patient to rate the severity of the hyperhidrosis

Is your sweating never noticeable and does not interfere with daily activities?

Is your sweating tolerable but sometimes interferes with daily activities?

Is your sweating barely tolerable and frequently interferes with daily activities?

Is your sweating intolerable and always interferes with daily activities?

pediatric patients between ten to 15 years of age. Mild anticholinergic side effects may be seen. ${ }^{27}$

Oxybutynin used as a $3 \%$ gel has a relatively long half-life of up to $84 \mathrm{~h}$ and hence has a longer duration of action than aluminum compounds. It is known to exert its action on remote sites such as exerting its effects for overactive bladder when used in the axilla. Higher concentrations of $10 \%$ are now being tried. Mild and transient anticholinergic side effects may be observed. ${ }^{28,29}$ Transdermal patches with a surface area of $39 \mathrm{~cm}^{2}$, impregnated with $36 \mathrm{mg}$ oxybutynin, applied twice a week, have been investigated as a treatment option. ${ }^{2}$

Umeclidinium bromide has also been investigated as a topical agent. ${ }^{23}$ Formaldehyde, tannic acid, and glutaraldehyde are not commonly used because they are irritating. ${ }^{17}$

\section{3 | Topical botulinum toxin}

Topical botulinum toxin type-A non-covalently coupled with a transport peptide was used in a randomized, double-blind, vehicle-controlled study which showed a $65 \%$ reduction in sweat production. ${ }^{30}$

\section{4 | Cryotherapy}

Topical cryotherapy using a surface nitrous oxide cryoprobe applicator has also been tried with the rationale of freeze-damaging the sweat glands. The results are encouraging and side effects included a small area of necrosis. ${ }^{31}$

\section{5 | Newer topicals}

Lipid nanoparticle-delivered myricetin, a flavonoid that inhibits the SNARE complex, has been shown to reduce sweating after skin application. A subcutaneous injection is more effective because topical application of myricetin causes its oxidation by enzymes on the skin. ${ }^{32}$

A phase three, double-blind, randomized-controlled study using 5\% sofpironium bromide gel applied to the axillae once daily at night for six weeks in 281 Japanese patients, demonstrated its efficacy and safety. ${ }^{33}$

\section{5 | SYSTEMIC TREATMENT}

Oral medication is reserved for treatment-resistant cases or generalized hyperhidrosis.

\section{1 | Anticholinergics}

These are the most used oral medications. However, one-third of patients discontinue treatment due to side effects. They are not US FDA approved. ${ }^{18}$ The dose is gradually escalated to improve tolerability. Adverse effects include drying of secretions, hyperthermia, orthostatic hypotension, dizziness, drowsiness, and blurred vision. ${ }^{34}$ They are contraindicated in patients with pyloric stenosis, paralytic ileus, and myasthenia gravis. ${ }^{35}$

Glycopyrrolate is the most used drug. It is a quaternary amine, and since it has limited ability to cross the lipid membranes and has fewer side effects. The starting dose is one to two mg daily. ${ }^{35} \mathrm{~A}$ recent open label single arm study concluded that low-dose glycopyrrolate, $2 \mathrm{mg}$ daily for 6 weeks is a cost-effective, safe, and efficacious treatment reducing the HDSS score by two points. ${ }^{36}$ Oxybutynin is a tertiary amine and is lipid permeable. It is started at a dose of $2.5 \mathrm{mg}$ daily and escalated to $10-15 \mathrm{mg}$ daily. ${ }^{35}$ Bornaprine also a tertiary amine has also been studied in the dose of 2-4 mg and found to be effective. ${ }^{23}$ Methantheline bromide is approved for the use in $\mathrm{AH}$ in Germany. In a randomized, placebo-controlled trial, it was found to be effective and safe in $\mathrm{AH}^{37}$

\section{2 | Alpha-Adrenergic agonists}

Clonidine, an alpha-2 adrenergic agonist, reduces sympathetic outflow and reduces sweating due to paroxysmal localized hyperhidrosis. ${ }^{18}$ It is given in the dose of $0.1 \mathrm{mg}$ twice daily. It can cause hypotension. $^{38}$

\subsection{Calcium channel blockers and other drugs}

These agents inhibit the calcium-dependent acetylcholine release and help to reduce sweating. ${ }^{18}$ Other potential oral drugs are beta-blockers and benzodiazepines which reduce anxiety-related hyperhidrosis. ${ }^{18}$

\subsection{Injectable treatments}

Botulinum toxin (BTX) acts by blocking the acetylcholine at the neuromuscular synapse. OnabotulinumtoxinA is a US FDA-approved treatment for severe, primary $\mathrm{AH}$. All three formulations of BTXA, ona, abo, and inco and rimabotulinumtoxin (BTXB) are also used. BTXB exhibits a quicker onset of action but a shorter duration. ${ }^{39}$ Some of the contraindications to the use of BTX are neuromuscular disorders, allergy to any of the components of the toxin, pregnancy, 
TABLE 1 Treatment options in axillary hyperhidrosis

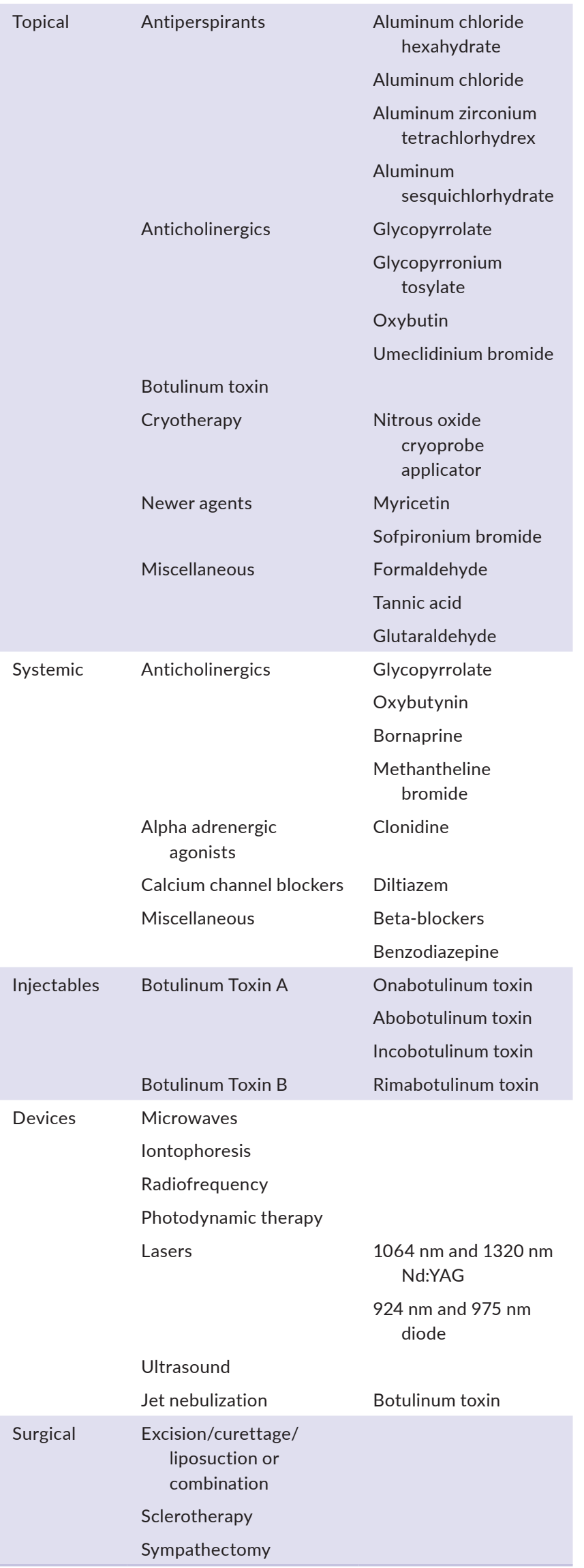

and lactation. ${ }^{18}$ Injections are at the subdermal level and not more than 400 units of onabotulinum should be injected over a 4-month period. One mouse unit of onabotulinum is equivalent to three of abo and 40 of rimabotulinumtoxin. ${ }^{39,40}$

In a randomized parallel-group placebo-controlled trial with onabotulinumtoxin A in 320 patients, 94\% achieved an endpoint of greater than or equal to $50 \%$ reduction in axillary sweating from the baseline and $82 \%$ maintained this endpoint at week $16 .{ }^{13}$ Repeat dosing after axillary sweat-reduction period of around 5 months is safe with potentially increased or equal efficacy. ${ }^{41}$ Other studies have also shown an efficacy of greater than $90 \%$, with greater improvement within the first 22 weeks but effects lasting only 4-9 months. ${ }^{18}$

Injection site pain is common and axillary itching, headache, and shoulder muscle soreness are less reported transient adverse effects. ${ }^{42}$ Recently, a novel approach for drug delivery of onabotulinumtoxin $A$ has been applied to diminish the pain feeling relating to the injection. Agamia et al showed that 75 units of BoNTA to the dermis on the right-sided palms assisted by fractional $\mathrm{CO}_{2}$ laser was clinically equivalent to 50 units of injection on the left side of 30 adults patients with idiopathic palmar hyperhidrosis. ${ }^{43}$ Moreover, it has been shown that repetitive therapy with botulinum toxin injections results in a significant reduction in perspiration and improved quality of life. ${ }^{44}$ A 5 -year follow-up of 75 patients suffered.

Who were injected intra-dermal botulinum toxin type-A for $\mathrm{AH}$ demonstrated significant improvement of quality of life (QoL) assessed by the modified Dermatology Life Quality Index (DLQI). ${ }^{45}$

\section{6 | DEVICE-BASED TREATMENTS}

\section{1 | Microwaves}

Microwave thermolysis is used for the treatment of hyperhidrosis. MiraDry ${ }^{\circledR}$ is a US FDA-approved device for this. ${ }^{2}$ It provides longterm efficacy with minimal transient side effects of local inflammation. Usually, two but sometimes several treatment sessions may be needed. ${ }^{46,47}$ The treatment efficacy is $72.5 \%-90 \%$ after 1 -year follow-up compared to $90 \%$ with surgical treatments. ${ }^{47,48} \mathrm{~A}$ randomized, blinded clinical study revealed that treatment efficacy was stable from $74 \%$ at 3 months to $69 \%$ at 12 months in the group treated with the microwave technology. ${ }^{47}$ The treatment is performed under tumescent anesthesia and entails fibrosis of the sweat glands caused by the microwaves. ${ }^{49}$

\section{2 | Iontophoresis}

Tap water iontophoresis is a safe and cost-effective US FDAapproved treatment for palmoplantar hyperhidrosis, and special axillary electrodes have been developed for its use in $\mathrm{AH} .{ }^{50}$ The treatment uses galvanic current through undamaged skin immersed in liquid. There are various theories proposed to suggest 


\section{BOX 2 General advice to patients with Axillary hyperhidrosis ${ }^{2,18}$}

Wear loose-fitting cotton clothing

Stay in a cool environment

Supplement for lost electrolytes and minerals in the sweat

Avoid triggers such as spicy foods, alcohol, crowded areas, and emotional triggers

Underarm liners, pads, or dress shields may be used

Relaxation techniques should be discussed to cut down on the psychological impact

the mechanism of action of this treatment from reduction in the $\mathrm{pH}$ due to $\mathrm{H}+$ ion accumulation, sympathetic nerve stimulation blockage, interference with the electrochemical gradient of sweat, blockage of sweat secretion, and flow by a hyperkeratotic plug. ${ }^{51-53}$ Usually, a current of 15-20 mA is used for 20- to 30-minute sessions three to four times a week. Maintenance treatments are done every one to four weeks after anhidrosis is achieved in six to fifteen treatments. ${ }^{54,55}$ Tap water can be replaced by aluminum chloride, anticholinergic agents, or botulinum toxin to achieve better results. Saline proved to be more effective than tap water in a study. ${ }^{56}$ Patients who are pregnant, have metal implants, pacemakers or have epilepsy cannot take the treatment. ${ }^{18}$ Transient $^{1}$ vesiculation, redness, paresthesia, and discomfort are the side effects. $^{57,58}$

\section{3 | Radiofrequency}

Microneedle radiofrequency (MNRF) is a promising modality for the treatment of $\mathrm{AH}$. Abtahi-Naeini B et al. in their single-blind shamcontrolled study concluded that there was a positive therapeutic effect with the use of fractionated MNRF technology on HDSS and that the treatment may be repeated after a year. Relapse significantly correlated with body mass index. ${ }^{59}$ The mechanism of action is by ablation of the eccrine glands by heating the hypodermis. In a case report, a 29-year-old lady was treated with recalcitrant bilateral $\mathrm{AH}$ with fractionated MNRF with a clear reduction of sweat glands seen in her post-treatment biopsy samples compared to the baseline. $^{60}$

\section{4 | Photodynamic therapy}

The use of a topical liposomal eosin hydrogel activated with intense pulsed light (IPL) showed to be a safe treatment for $\mathrm{AH}$. Twenty patients were treated in one axilla with a $400 \mathrm{~nm}$ filter and $20 \mathrm{~ms}$ duration with IPL once weekly for 4 weeks and reported a $90.1 \%$ decrease in hyperhidrosis in the treated axilla. ${ }^{2}$

\subsection{Lasers}

In a randomized-controlled half-side comparison study with 21 patients treated with five cycles of a long-pulsed 800-nm diode laser, laser epilation did not reduce the sweat rates significantly more than on the untreated contralateral side. The results were more of a placebo effect rather than a direct therapeutic effect of the laser. ${ }^{61}$ In another prospective case-controlled randomized pilot study, a longpulsed Nd:YAG 1064-nm laser was used at hair reduction settings. Treatments were done at monthly intervals on one axilla with the other acting as a control. Though there were no histological differences between the two sides pre- and post-treatment, statistically significant differences were seen subjectively and objectively between the treated and non-treated sides for at least 9 months. ${ }^{62}$ Subdermal laser procedures using 1064 and 1320 Nd:YAG lasers and 924-nm and 975-nm diode lasers have been used as they cause microvesiculation, desquamation, or vaporization of the sweat glands. ${ }^{63}$ Another study involving 17 patients using subdermal $\mathrm{Nd}$ YAG laser for $\mathrm{AH}$ reported significant clinical improvement. ${ }^{64}$ Side effects include edema, burns, hair reduction, decreased sensation, and pain. ${ }^{64}$ A study in which 1064-nm Nd:YAG laser was used found $\mathrm{AH}$ to increase after treatment. ${ }^{65}$

Laser lipolysis with $300 \mathrm{~mm}$ fiber showed a mean sweat reduction of $72 \%$ and another showed a mean sweat reduction of $93 \%$ with $600 \mathrm{~mm}$ fiber. $^{2}$

\section{6 | Ultrasound}

Micro-focused ultrasound plus visualization is an effective and welltolerated treatment for $\mathrm{AH}$. Results of two randomized, doubleblind, sham-controlled pilot studies reported high levels of patient satisfaction in terms of reduction in baseline sweat reduction. Patients only reported minor transient discomfort during the procedure but no pain. Results persisted for at least a year. ${ }^{66}$ Vibration of tissues resulting in thermal injury to the eccrine glands is the postulated mechanism of action. ${ }^{67}$

\subsection{Jet nebulization}

To circumvent the pain associated with intra-dermal injections, a medical device, JetPeel ${ }^{\mathrm{TM}}-3$, was used for the transdermal delivery of botulinum toxin. ${ }^{68}$

\section{7 | SURGICAL MANAGEMENT}

Surgery is advised when other conventional therapies fail. Local surgical approaches consist of excision, curettage, liposuction, and/or a combination of these. Conservative excision called "Shelly procedure" scores over radical excision which may lead to scarring and restricted arm movement. Liposuction and curettage using a cannula 
eliminates the axillary sweat glands almost completely. ${ }^{69}$ It does not cause scarring but may lead to seroma, brachial plexus injury, pain, hemorrhage, hair loss, and even compensatory hyperhidrosis. ${ }^{69}$

A study on 43 patients with axillary bromhidrosis treated with a local surgical excision yielded good results in improving the malodor and reducing sweat production with complications of skin necrosis in two and hematomas in three patients only. The quality of life improved in all patients after the surgery. ${ }^{70}$

In a series of 12 cases of axillary osmidrosis ablation of axillary apocrine glands by minimal subdermal shaving using sclerotherapy with absorbable ethanol was performed. The results of this simple technique showed good objective improvement with no complications of hematoma or seroma formation. ${ }^{71}$

Thoracoscopic sympathetic surgery has been evaluated to determine the optimal level of sympathetic trunk interruption by clipping and to assess postoperative compensatory sweating, patients satisfaction, and QoL, showing that thoracoscopic R3 to R4 clipping appears to be a safe and effective treatment for primary palmar and/or $\mathrm{AH}^{72}$ Surgical options could be offered based on each patients' condition even in younger age groups as an analysis of 639 adults and adolescences patients who underwent Video Assisted Thoracoscopic Sympathectomy (VATS) manifested that adolescent patients could benefit from VATS performed as the same level of adult patients. $^{73}$

\section{1 | Sympathectomy}

This is the last resort when all other therapies have failed. A metaanalysis of articles on open versus closed surgery of axillary osmidrosis concluded that closed surgery was safer but less effective than open surgery. ${ }^{74}$ The most dreaded long-term complication of sympathectomy is compensatory hyperhidrosis, seen in up to $98 \%$ patients. Preferred patients are those younger than 25 years of age, those with a body mass index of less than $28 \mathrm{~kg} / \mathrm{m}^{2}$ and do not have bradycardia or nocturnal sweating. ${ }^{75}$ The T3-T4 ganglia are targeted with endoscopic sympathectomy in $\mathrm{AH}$. It is effective in $66.7 \%$ $100 \%$ patients, ${ }^{75}$ but its effectiveness decreases with time. ${ }^{76}$

In a comparative study between two levels of sympathectomy T3T4 versus T4 in 64 patients followed up for 1 year, success was seen in all patients with an improvement in the quality of life in all that 6 month and 1-year follow-up. The compensatory hyperhidrosis, however, was significantly increased in the T3-T4 group compared to the T4 group at both intervals. In fact, $100 \%$ patients with the two-level surgery had compensatory hyperhidrosis compared to only $42.4 \%$ in the single level T4 group. Single level T4 video-assisted thoracoscopic sympathectomy proved superior to a two-level T3-T4 one. ${ }^{77}$

\section{2 | Adjunctive therapies}

The International Hyperhidrosis Society's website http://www. sweathelp.org is an educative platform for patients suffering from hyperhidrosis. Clothing and bedsheets that can wick-away moisture may also be useful adjuvants to the overall management. ${ }^{25}$

\section{8 | CONCLUSION}

$\mathrm{AH}$ is a chronic autonomic disorder resulting in social embarrassment and impaired quality of life. The condition is usually associated with palmoplantar hyperhidrosis. Diagnosis the cause is important in its management. Several treatment options including topical therapy, systemic therapy, injectables, newer devices, and surgical procedures are available for the treatment of $\mathrm{AH}$. Patient education is important aspect of the management. Individualized approach of management is necessary for optimal outcome of treatment.

\section{ACKNOWLEDGEMENT}

Open Access funding enabled and organized by Projekt DEAL.

\section{AUTHOR CONTRIBUTIONS}

Gulhima Arora: Writing and revising the manuscript. Martin Kassir: Review and revising the manuscript. Anant Patil: Review and revising the manuscript. Payam Sadeghi: Review and revising the manuscript. Michael H. Gold: Review and revising the manuscript. Maurice Adatto: Review and revising the manuscript. Stephan Grabbe: Review and revising the manuscript. Petra Staubach-Renz: Conception, writing, review, and revising the manuscript.

\section{ETHICAL APPROVAL}

Review article no subjects were used.

\section{DISCLAIMER}

"We confirm that the manuscript has been read and approved by all the authors, that the requirements for authorship as stated earlier in this document have been met and that each author believes that the manuscript represents honest work".

\section{DATA AVAILABILITY STATEMENT}

The data that support the findings of this study are available from the corresponding author upon reasonable request.

\section{ORCID}

Gulhima Arora (D) https://orcid.org/0000-0002-8365-3124

Anant Patil (D) https://orcid.org/0000-0002-9455-4025

Payam Sadeghi (D) https://orcid.org/0000-0003-2097-7559

Michael H. Gold (D) https://orcid.org/0000-0002-5183-5433

Mohamad Goldust (D) https://orcid.org/0000-0002-8646-1179

\section{REFERENCES}

1. Wadhawa S, Agrawal S, Chaudhary M, Sharma S. Hyperhidrosis prevalence: a disease underreported by patients and underdiagnosed by physicians. Indian Dermatol Online J. 2019;10:676-681.

2. Sammons JE, Khachemoune A. Axillary hyperhidrosis: a focused review. J Dermatolog Treat. 2017;28:582-590. 
3. Herbst F, Plas EG, Függer R, Fritsch A. Endoscopic thoracic sympathectomy for primary hyperhidrosis of the upper limbs. A critical analysis and long-term results of 480 operations. Ann Surg. 1994;220:86-90.

4. Hamm H, Naumann MK, Kowalski JW, Kütt S, Kozma C, Teale C. Primary focal hyperhidrosis: disease characteristics and functional impairment. Dermatology. 2006;212:343-353.

5. Stolman LP. Hyperhidrosis: medical and surgical treatment. Eplasty. 2008;8:e22.

6. Doolittle J, Walker P, Mills T, Thurston J. Hyperhidrosis: an update on prevalence and severity in the United States. Arch Dermatol Res. 2016;308:743-749.

7. Baker LB. Physiology of sweat gland function: the roles of sweating and sweat composition in human health. Temperature (Austin). 2019;6:211-259.

8. Sato K, Kang WH, Saga K, Sato KT. Biology of sweat glands and their disorders. I. Normal sweat gland function. J Am Acad Dermatol. 1989;20:537-563.

9. Schnider P, Binder M, Auff E, Kittler H, Berger T, Wolff K. Doubleblind trial of botulinum A toxin for the treatment of focal hyperhidrosis of the palms. Br J Dermatol. 1997;136:548-552.

10. Lakraj A-AD, Moghimi N, Jabbari B. Hyperhidrosis: anatomy, pathophysiology and treatment with emphasis on the role of botulinum toxins. Toxins (Basel). 2013;5:821-840.

11. Shibasaki M, Crandall CG. Mechanisms and controllers of eccrine sweating in humans. Front Biosci (Schol Ed). 2010;2:685-696.

12. Hodge BD, Sanvictores T \& Brodell RT Anatomy, skin sweat glands. In: StatPearls [Internet]. Treasure Island (FL): StatPearls Publishing; 2021 [cited 2021 May 4]. Available from: http://www.ncbi.nlm.nih gov/books/NBK482278/. Accessed 2021 Jan-

13. Saadia D, Voustianiouk A, Wang AK, Kaufmann H. Botulinum toxin type $A$ in primary palmar hyperhidrosis: randomized, single-blind, two-dose study. Neurology. 2001;57:2095-2099.

14. Kellogg DL. In vivo mechanisms of cutaneous vasodilation and vasoconstriction in humans during thermoregulatory challenges. $J$ Appl Physiol (1985). 2006;100(5):1709-1718.

15. Kummer W, Herbst WM, Heym C. Vasoactive intestinal polypeptide receptor-like immunoreactivity in human sweat glands. Neurosci Lett. 1990;110:239-243.

16. Hornberger J, Grimes K, Naumann M, et al. Recognition, diagnosis, and treatment of primary focal hyperhidrosis. J Am Acad Dermatol. 2004;51:274-286

17. Walling HW, Swick BL. Treatment options for hyperhidrosis. Am J Clin Dermatol. 2011;12:285-295.

18. Nawrocki S, Cha J. The etiology, diagnosis, and management of hyperhidrosis: a comprehensive review. J Am Acad Dermatol. 2019;81:669-680.

19. Hölze E. Therapy of hyperhidrosis. Hautarzt. 1984;35:7-15.

20. Scholes KT, Crow KD, Ellis JP, Harman RR, Saihan EM. Axillary hyperhidrosis treated with alcoholic solution of aluminium chloride hexahydrate. Br Med J. 1978;2:84-85.

21. Glent-Madsen L, Dahl JC. Axillary hyperhidrosis. Local treatment with aluminium-chloride hexahydrate $25 \%$ in absolute ethanol with and without supplementary treatment with triethanolamine. Acta Derm Venereol. 1988;68:87-89.

22. Pariser DM, Ballard A. Topical therapies in hyperhidrosis care. Dermatol Clin. 2014;32:485-490.

23. Hosp C, Hamm H. Safety of available and emerging drug therapies for hyperhidrosis. Expert Opin Drug Saf. 2017;16:1039-1049.

24. Innocenzi D, Lupi F, Bruni F, Frasca M, Panetta C, Milani M. Efficacy of a new aluminium salt thermophobic foam in the treatment of axillary and palmar primary hyperhidrosis: a pilot exploratory trial. Curr Med Res Opin. 2005;21:1949-1953.

25. Grabell DA, Hebert AA. Current and emerging medical therapies for primary hyperhidrosis. Dermatol Ther (Heidelb). 2017;7:25-36.

26. Mackenzie A, Burns C, Kavanagh G. Topical glycopyrrolate for axillary hyperhidrosis. Br J Dermatol. 2013;169:483-484.
27. Hebert AA, Glaser DA, Green L, et al. Long-term efficacy and safety of topical glycopyrronium tosylate for the treatment of primary axillary hyperhidrosis: post hoc pediatric subgroup analysis from a 44-week open-label extension study. Pediatr Dermatol. 2020;37:490-497.

28. Trindade de Almeida AR, de Moura Moreira VR, Ferrari F. Topical and systemic anticholinergic for treating hyperhidrosis. Shanghai Chest. 2019;3:41.

29. Nguyen NV, Gralla J, Abbott J, Bruckner AL. Oxybutynin 3\% gel for the treatment of primary focal hyperhidrosis in adolescents and young adults. Pediatr Dermatol. 2018;35:208-212.

30. Glaser DA, Galperin TA. Managing hyperhidrosis: emerging therapies. Dermatol Clin. 2014;32:549-553.

31. Ashby EC, Williams JL. Cryosurgery for axillary hyperhidrosis. $\mathrm{Br}$ Med J. 1976;2:1173-1174.

32. Ban C, Park J-B, Cho S, et al. Reduction of focal sweating by lipid nanoparticle-delivered myricetin. Sci Rep. 2020;10:13132.

33. Yokozeki H, Fujimoto T, Abe $\mathrm{Y}$, et al. A phase 3, multicenter, randomized, double-blind, vehicle-controlled, parallel-group study of $5 \%$ sofpironium bromide (BBI-4000) gel in Japanese patients with primary axillary hyperhidrosis. J Dermatol. 2021;48:279-288.

34. Toledo-Pastrana T, Márquez-Enríquez J, Millán-Cayetano JF. Oral oxybutynin for local and multifocal hyperhidrosis: a multicenter study. Actas Dermosifiliogr. 2017;108:597-599.

35. Bajaj $\mathrm{V}$, Langtry JAA. Use of oral glycopyrronium bromide in hyperhidrosis. Br J Dermatol. 2007;157:118-121.

36. Vyas K, Singh R, Kumari A, Balai M. Evaluation of efficacy and safety of low dose glycopyrrolate in management of primary hyperhidrosis--an open label single arm study. Indian Dermatol Online J. 2020;11:1012-1013.

37. Müller $\mathrm{C}$, Berensmeier $\mathrm{A}$, Hamm $\mathrm{H}$, et al. Efficacy and safety of methantheline bromide (Vagantin(囚)) in axillary and palmar hyperhidrosis: results from a multicenter, randomized, placebo-controlled trial. J Eur Acad Dermatol Venereol. 2013;27:1278-1284.

38. Walling HW. Systemic therapy for primary hyperhidrosis: a retrospective study of 59 patients treated with glycopyrrolate or clonidine. J Am Acad Dermatol. 2012;66:387-392.

39. Baumann L, Slezinger A, Halem M, et al. Double-blind, randomized, placebo-controlled pilot study of the safety and efficacy of Myobloc (botulinum toxin type B) for the treatment of palmar hyperhidrosis. Dermatol Surg. 2005;31:263-270.

40. Yamauchi PS, Lowe NJ. Botulinum toxin types A and B: comparison of efficacy, duration, and dose-ranging studies for the treatment of facial rhytides and hyperhidrosis. Clin Dermatol. 2004;22:34-39.

41. Odderson IR. Long-term quantitative benefits of botulinum toxin type $A$ in the treatment of axillary hyperhidrosis. Dermatol Surg. 2002;28:480-483.

42. Stuart ME, Strite SA, Gillard KK. A systematic evidence-based review of treatments for primary hyperhidrosis. J Drug Assess. 2020;10:35-50.

43. Agamia N, Sobny N, Abd-Elraouf A, Tawfik A. Fractional CO2 Laser for transcutaneous drug delivery of onabotulinum toxin in palmar hyperhidrosis. Dermatol Surg. 2021;47:678-683.

44. Baghchechi M, Kenneth M, Sharon J. Axillary botulinum toxin injection for the treatment of moderate to severe hyperhidrosis. $J$ Dermatol Nurses Assoc. 2021;13:67-69.

45. Lunch OE, Aherne T, Gibbons J, et al. Five-year follow-up of patients treated with intra-dermal botulinum toxin for axillary hyperhidrosis. Ir J Med Sci. 2020;189:1023-1026.

46. Patel F, Tu YM, Fernandes S, Chapas A. A case of axillary bromhidrosis secondary to trimethylaminuria successfully treated with microwave-based therapy. JAAD Case Rep. 2019;5:915-917.

47. Glaser DA, Coleman WP, Fan LK, et al. A randomized, blinded clinical evaluation of a novel microwave device for treating axillary hyperhidrosis: the dermatologic reduction in underarm perspiration study. Dermatol Surg. 2012;38:185-191. 
48. Scuderi S, Manoharan P, Lim D, Manoharan S. A survey of patient satisfaction with use of microwave device for axillary hyperhidrosis. Australas J Dermatol. 2017;58:126-129.

49. Sánchez-Carpintero I, Martín-Gorgojo A, Ruiz-Rodríguez R. Microwave treatment for axillary hyperhidrosis and bromhidrosis. Actas Dermosifiliogr. 2017;108:418-422.

50. Wörle B, Rapprich S, Heckmann M. Definition and treatment of primary hyperhidrosis. J Dtsch Dermatol Ges. 2007;5:625-628.

51. Sato K, Timm DE, Sato F, et al. Generation and transit pathway of $\mathrm{H}+$ is critical for inhibition of palmar sweating by iontophoresis in water. J Appl Physiol (1985). 1993;75:2258-2264.

52. Stolman LP. Treatment of excess sweating of the palms by iontophoresis. Arch Dermatol. 1987;123:893-896.

53. Hill AC, Baker GF, Jansen GT. Mechanism of action of iontophoresis in the treatment of palmar hyperhidrosis. Cutis. 1981;28:69-70, 72.

54. Solish N, Bertucci V, Dansereau A, et al. A comprehensive approach to the recognition, diagnosis, and severity-based treatment of focal hyperhidrosis: recommendations of the Canadian Hyperhidrosis Advisory Committee. Dermatol Surg. 2007;33:908-923.

55. Shrivastava SN, Singh G. Tap water iontophoresis in palmo-plantar hyperhidrosis. Br J Dermatol. 1977;96:189-195.

56. Yaghobi Z, Goljarian S, Oskouei AE. Comparison of tap water and normal saline iontophoresis in idiopathic hyperhidrosis: a case report. J Phys Ther Sci. 2014;26:1313-1315.

57. Choi YH, Lee S-J, Kim DW, Lee WJ, Na GY. Open clinical trial for evaluation of efficacy and safety of a portable "dry-type" iontophoretic device in treatment of palmar hyperhidrosis. Dermatol Surg. 2013;39:578-583.

58. Pariser DM, Ballard A. Iontophoresis for palmar and plantar hyperhidrosis. Dermatol Clin. 2014;32:491-494.

59. Abtahi-Naeini B, Naeini FF, Saffaei A, et al. Treatment of primary axillary hyperhidrosis by fractional microneedle radiofrequency: is it still effective after long-term follow-up? Indian J Dermatol. 2016;61:234.

60. Fatemi Naeini F, Pourazizi M, Abtahi-Naeini B, Nilforoushzadeh MA, Najafian J. A novel option for treatment of primary axillary hyperhidrosis: fractionated microneedle radiofrequency. J Postgrad Med. 2015;61:141-143.

61. Bechara FG, Georgas D, Sand M, et al. Effects of a long-pulsed 800$\mathrm{nm}$ diode laser on axillary hyperhidrosis: a randomized controlled half-side comparison study. Dermatol Surg. 2012;38:736-740.

62. Letada PR, Landers JT, Uebelhoer NS, Shumaker PR. Treatment of focal axillary hyperhidrosis using a long-pulsed Nd:YAG $1064 \mathrm{~nm}$ laser at hair reduction settings. J Drugs Dermatol. 2012;11:59-63.

63. Leclère FM, Moreno-Moraga J, Alcolea JM, et al. Efficacy and safety of laser therapy on axillary hyperhidrosis after one year follow-up: a randomized blinded controlled trial. Lasers Surg Med. 2015;47:173-179.

64. Goldman A, Wollina U. Subdermal Nd-YAG laser for axillary hyperhidrosis. Dermatol Surg. 2008;34:756-762.

65. Aydin F, Pancar GS, Senturk N, et al. Axillary hair removal with 1064-nm Nd:YAG laser increases sweat production. Clin Exp Dermatol. 2010;35:588-592.
66. Nestor MS, Park H. Safety and efficacy of micro-focused ultrasound plus visualization for the treatment of axillary hyperhidrosis. J Clin Aesthet Dermatol. 2014;7:14-21.

67. Laubach HJ, Makin IRS, Barthe PG, Slayton MH, Manstein D. Intense focused ultrasound: evaluation of a new treatment modality for precise microcoagulation within the skin. Dermatol Surg. 2008;34:727-734.

68. Iannitti T, Palmieri B, Aspiro A, Di Cerbo A. A preliminary study of painless and effective transdermal botulinum toxin A delivery by jet nebulization for treatment of primary hyperhidrosis. Drug Des Devel Ther. 2014;8:931-935.

69. Payne CM, Doe PT. Liposuction for axillary hyperhidrosis. Clin Exp Dermatol. 1998;23:9-10.

70. Van TN, Manh TN, Minh PPT, et al. The effectiveness of local surgical technique in treatment of axillary bromhidrosis. Open Access Maced J Med Sci. 2019;7:187-191.

71. Shim H-S, Min S-K, Lim J-S, Han K-T, Kim M-C. Minimal subdermal shaving by means of sclerotherapy using absolute ethanol: a new method for the treatment of axillary osmidrosis. Arch Plast Surg. 2013;40:440-444.

72. Nachira D, Meacci E, Congedo MT, et al. Rib-oriented thoracoscopic sympathetic surgery for hyperhidrosis: prospective longterm results and quality of life. Surg Laparosc Endosc Percutan Tech. 2021;31:307-312. https://doi.org/10.1097/SLE.0000000000 000925

73. Wolosker N, Faustino CB, de Campos JRM, et al. Comparative analysis of the results of videothoracoscopic sympathectomy in the treatment of hyperhidrosis in adolescent patients. J Pediatr Surg. 2020;55:418-424.

74. Nomura M, Morioka D, Kojima Y, Tanaka R, Kadomatsu K. Open versus closed surgery for axillary osmidrosis: a meta-analysis of articles published in four languages. Ann Dermatol. 2020;32:487-495.

75. Lin TS, Fang HY. Transthoracic endoscopic sympathectomy for craniofacial hyperhidrosis: analysis of 46 cases. J Laparoendosc Adv Surg Tech A. 2000;10:243-247.

76. Dumont P, Denoyer A, Robin P. Long-term results of thoracoscopic sympathectomy for hyperhidrosis. Ann Thorac Surg. 2004;78:1801-1807.

77. Chen S, Zhang P, Chai T, Shen Z, Kang M, Lin J. T3 versus T4 videoassisted thoracoscopic sympathectomy for palmar hyperhidrosis: a protocol for a systematic review and meta-analysis. Medicine (Baltimore). 2019;98:e17272.

How to cite this article: Arora G, Kassir M, Patil A, et al. Treatment of Axillary hyperhidrosis. J Cosmet Dermatol. 2022;21:62-70. https://doi.org/10.1111/jocd.14378 